\title{
Combined Odontogenic Tumors: Clinical, Radiographical and Histopathological Evaluation
}

\author{
Abdullah S. Al Mushayt, BDS, Pedi cert PhD and Ahmed O. Al \\ Yamani, BDS, CAGS, OMFS, DSc OMFS Dipl ABOMS, FFDRSCI \\ Departments of Oral Basic \& Clinical Sciences \\ and Oral \& Maxillofacial Rehabilitation, Faculty of Dentistry \\ King Abdulaziz University, Jeddah Saudi Arabia \\ ahmedalyanani@hotmail.com
}

\begin{abstract}
The combined epithelial odontogenic tumor is known to be an uncommon lesion characterized by the synchronous presentation of typical histological features of adenomatoid odontogenic tumor, calcifying epithelial odontogenic tumor, or Pindborg tumor. Combination between other types of odontogenic tumors has occasionally been reported in the literature. In this work we report 2 cases of adenomatoid odontogenic tumor associated with odontomas, one in a 16-year-old male patient and the other in an 11-year-old female child. The 2 cases, with this type of combination, seem to be the first reported in the literature. In addition, we report a third case of association between calcifying epithelial odontogenic cyst or Gorlin cyst and ameloblastoma in a 14-year-old female patient. This case seems also to be the fourth case reported in the literature. The cases reported in this present work were evaluated clinically, radiographically, and histologically.
\end{abstract}

Keywords: Odontogenic tumors, Combined odontogenic tumors, calcifying epithelial ondongenic cyst, adenomatoid odontogenic tumor.

\section{Introduction}

Odontogenic tumors are lesions derived from the epithelial and/or mesen'chymal remnants of the tooth forming apparatus. They are therefore, found exclusively in the mandible and maxilla, occasionally in

Correspondence $\&$ reprint requests to:

Dr. Abdullah S. Al Mushayt

P.O. Box 80209, Jeddah, 21589 Saudi Arabia

Accepted for publication: 18 November 2006. Received: 18 April 2006. 
the gingiva. These lesions also exhibit considerable histological variation and can be benign or malignant ${ }^{[1]}$. Several histological classification schemes have been devised for this complex group of lesions ${ }^{[2-4]}$.

The most recent to all is the World Health Organization (WHO) division of tumors into those that are composed of odontogenic epithelium with mature fibrous tissue, those that are composed of odontogenic epithelium with odontogenic ectomesenchyme with or without dental hard tissue formation, and those that are proliferation of mesenchyme and/or odontogenic ectomesenchyme with or without included odontogenic epithelium (Table 1$)^{[4]}$.

Table 1. WHO classification of benign odontogenic tumors.

\begin{tabular}{|c|c|}
\hline 1.) & $\begin{array}{cl}\text { Tumors derived from odontogenic epithelium } \\
\text { - } & \text { Ameloblastoma } \\
\text { - } & \text { Squamous odontogenic tumor } \\
\text { - } & \text { Calcifying epithelial odontogenic tumor (CEOT) } \\
\text { - } & \text { Adenomatoid odontogenic tumor (AOT) } \\
\text { - } & \text { Keratinizing cystic odontogenic tumor }\end{array}$ \\
\hline 2.) & $\begin{array}{l}\text { Tumors derived from both odontogenic epithelium and odontogenic } \\
\text { mesenchyme with or without dental hard tissue formation. } \\
\text { - Ameloblastic fibroma } \\
\text { - Ameloblastic fibrodentinoma } \\
\text { - Ameloblastic fibro-odontoma } \\
\text { - Odontomas (compound and complex) } \\
\text { - Odontoameloblastoma } \\
\text { - Calcifying cystic odontogenic tumor } \\
\text { - Dentinogenic ghost cell tumor }\end{array}$ \\
\hline 3.) & $\begin{array}{l}\text { Tumors derived from odontogenic mesenchyme and/or odontogenic } \\
\text { ectomesenchyme with or without included odontogenic epithelium. } \\
\text { - Odontogenic fibroma } \\
\text { - Odontogenic myxoma } \\
\text { - Cementoblastoma }\end{array}$ \\
\hline
\end{tabular}

The combination of two odontogenic tumors is a rarely reported finding ${ }^{[5]}$. The combined or complex odontogenic tumors are lesions characterized by the synchronous presentation of typical histological features of two odontogenic tumors ${ }^{[6]}$. In 1983, Damm et al. ${ }^{[7]}$ presented the first 2 cases of combined epithelial odontogenic tumors which contained areas diagnostic for both adenomatoid odontogenic tumor (AOT) and calcifying epithelial odontogenic tumor (CEOT) known as 
Pindborg tumor. The histological features, histogenesis, and suggested treatment were discussed in their report at that time.

The third case of the same previous combination has been reported in $1986^{[8]}$. This was followed by one additional case in $1987^{[9]}$; 5 cases in $1991^{[10]} ; 2$ cases in $1993^{[5]}$; one case in $1994^{[6]}$; and one case in $1996^{[11]}$. The most recent case of the same previous combination was reported by Mosqueda-Taylor et al. (2005) ${ }^{[12]}$.

Several combinations of other types of odontogenic tumors were also reported, e.g., a case of combined ameloblastoma and ameloblastic fibroma ${ }^{[13]}$; cases of combined calcifying epithelial odontogenic cyst (CEOC), also known as Gorlin cyst; one by Martin-Duverneuil et al. $(2001)^{[14]}$ and the other one by Pistoia et al. $(2001)^{[15]}$; and 3 cases of combined CEOC and ameloblastic fibroma ${ }^{[16]}$.

In search for odontogenic tumors in Faculty of Dentistry (FOD), King Abdulaziz University (KAU), we found 3 cases of combined odontogenic tumors, 2 of them of an exceptional combination of AOT and odontoma. Such a combination, which to our knowledge, has not previously been reported, led us to discuss the clinical, radiographic, and microscopic features of these tumors. In addition, we also report a third case of combined ameloblastoma and CEOC also known as Gorlin cyst. To our knowledge, it seems to be the fourth reported case in the literature.

\section{Patients and Methods}

A 16-year-old Jordanian male was referred to the FOD, KAU to restore his carious teeth. The patient had insignificant medical and family history and was visiting the dental clinic for the first time. Intra- and extra-oral clinical examinations revealed nothing abnormal except for multiple carious teeth.

Radiographically, the panoramic and periapical X-ray pictures showed a mixed radiopaque and radiolucent area between the roots of lower right lateral incisor and canine teeth (Fig. 1 and 2). The radiographic differential diagnosis included AOT, CEOT, CEOC, and ossifying fibroma. The whole lesion was surgically excised and sent to Oral Pathology Division for microscopic examination. 


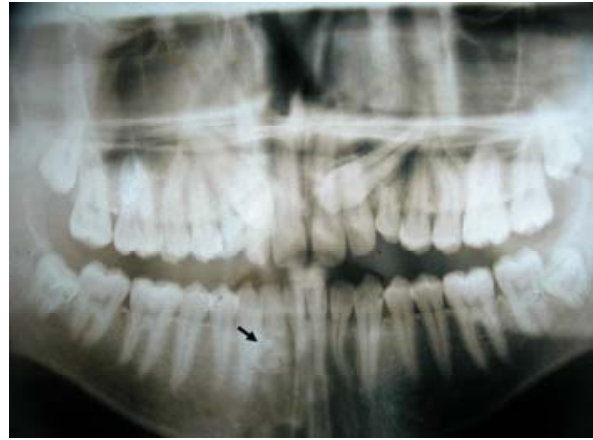

Fig 1. Case 1: Panoramic X-ray showing a mixed radiolucent and radiopaque lesion between the roots of lower right lateral incisor and canine teeth (see arrow).

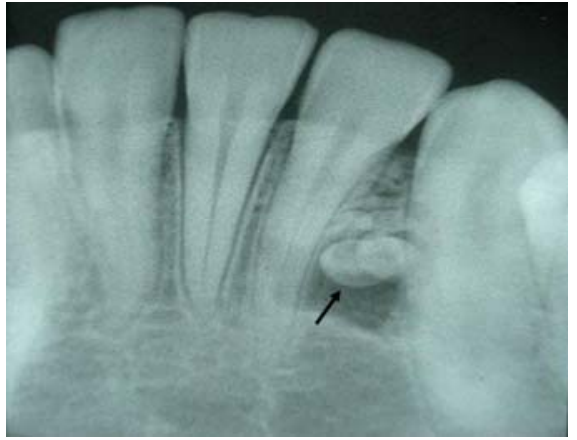

Fig. 2. Case 1: A periapical film showing the lesion in Fig.1 from the lingual side (see arrow).

The second case was an 11-year-old Saudi female who came to the dental clinic to correct her removable orthodontic appliance and restore her tilted lower left last molar. A thorough clinical examination was done to the patient with reference to the Orthodontic Division.

Panoramic and periapical radiographs were taken and examined. The radiographic pictures showed a mixed radiolucent and radiopaque area related to the roots of the lower right first molar (Fig. 3 and 4). The radiographical differential diagnosis included AOT, CEOT, CEOC, and ossifying fibroma. The lesion was removed surgically and treated as an excisional biopsy, which was sent for histopathological examination.



Fig. 3. Case 2: Panoramic X-ray showing a mixed radiolucent and radiopaque lesion related to the roots of the lower right last deciduous molar (see arrow).

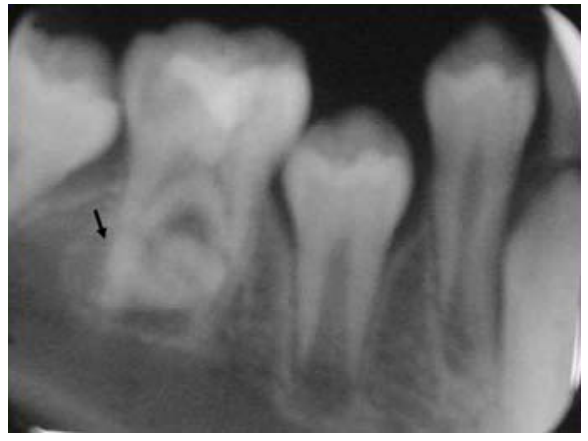

Fig. 4. A periapical $X$-ray for the same lesion in Fig 3. (see arrow). 
The third case was of a 14-year old Sudanese female who was complaining of a swelling on the left side of the mandible that started several months ago. The medical, dental, and family histories of the patient were not significant.

Extra oral examinations revealed a hard swelling in the posterior area of the left side of the mandible causing mild asymmetry. Intraoral, there was a bony mandibular expansion, which was obvious in the buccal side (Fig. 5).

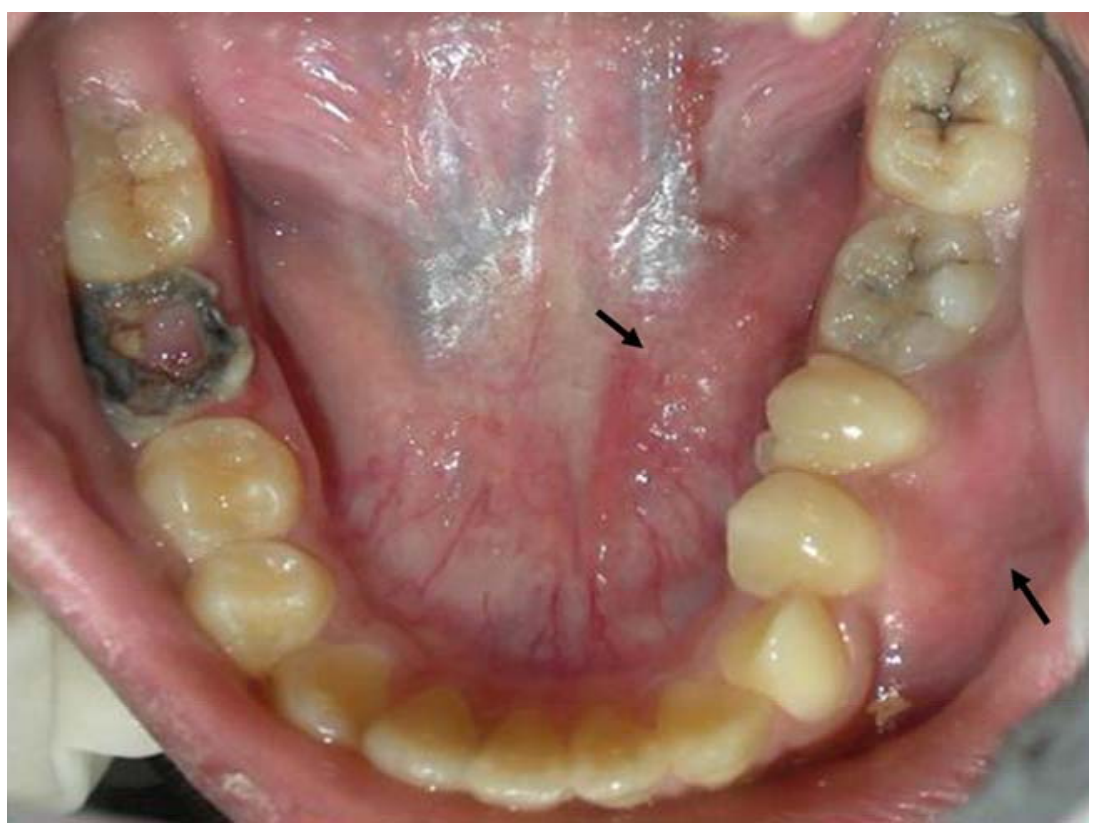

Fig. 5. Case 3: A photograph showing lingual and buccal bony expansion in the lower right premolar-molar area (see arrows).

Several radiographic (panoramic, anteroposterior, and occlusal) pictures were taken of the lesion (Fig. 6,7 and 8). These radiographs showed a radiolucent lesion related to the lower left premolar-first molar area. The radiographic differential diagnosis of this lesion was a developmental cyst, ameloblastoma and ameloblastic fibroma. A computerized tomography scan (CT scan) and three-dimension radiographs were also taken (Fig. 9 and 10). An incisional biopsy was taken for histological examination. 


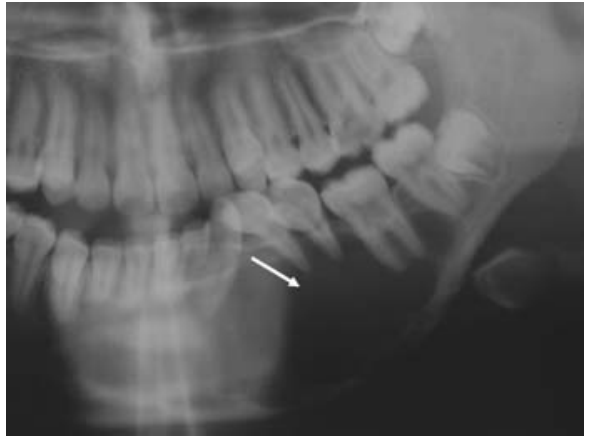

Fig. 6. Case 3: Panoramic X-ray showing a radiolucent lesion in the left mandibular premolar-molar area (see arrow).

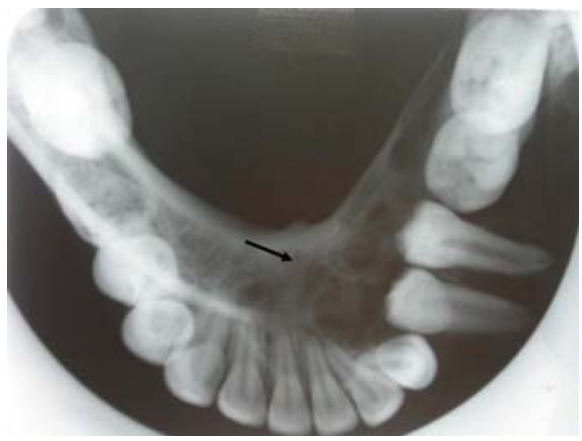

Fig. 8. Case 3: An occlusal radiograph (see arrow).

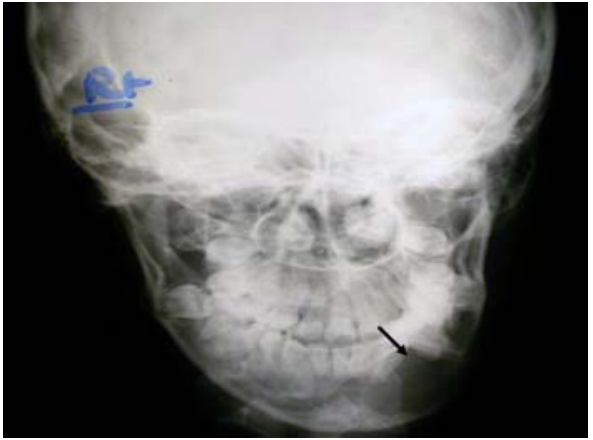

Fig. 7. Case 3: Anteroposterior X-ray showing a radiolucent lesion in the left side of the mandible (see arrow).

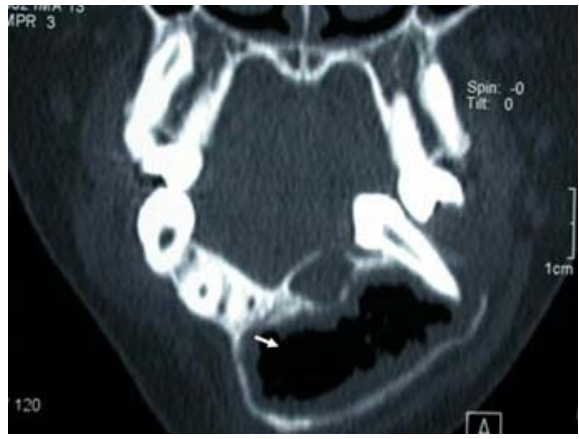

Fig. 9. Case 3: A CT scan showing the same lesion in Figs. 5, 8 (see arrow).

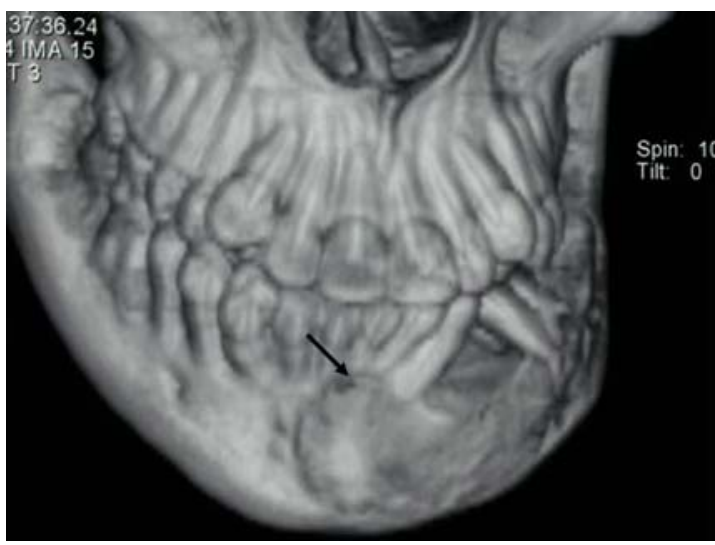

Fig. 10. Case 3: Three-dimension radiograph (see arrow). 
All the biopsy specimens were processed in the histopathology laboratory, embedded in paraffin wax, cut into 4 micron tissue sections and stained with hematoxylin and eosin (H\&E). All tissue sections were examined by the light microscope for diagnosis and tumor typing.

\section{Results}

The histological picture of the first case's biopsy revealed proliferation of odontogenic epithelial cells in the form of small masses and strands with some duct-like structures (Fig. 11a). Sheets of mature hard dental material (dentin, enamel, and cement) and connective tissue in an arrangement resembling tooth structure were also seen (Fig. 11b). The final diagnosis was AOT associated with compound odontoma.
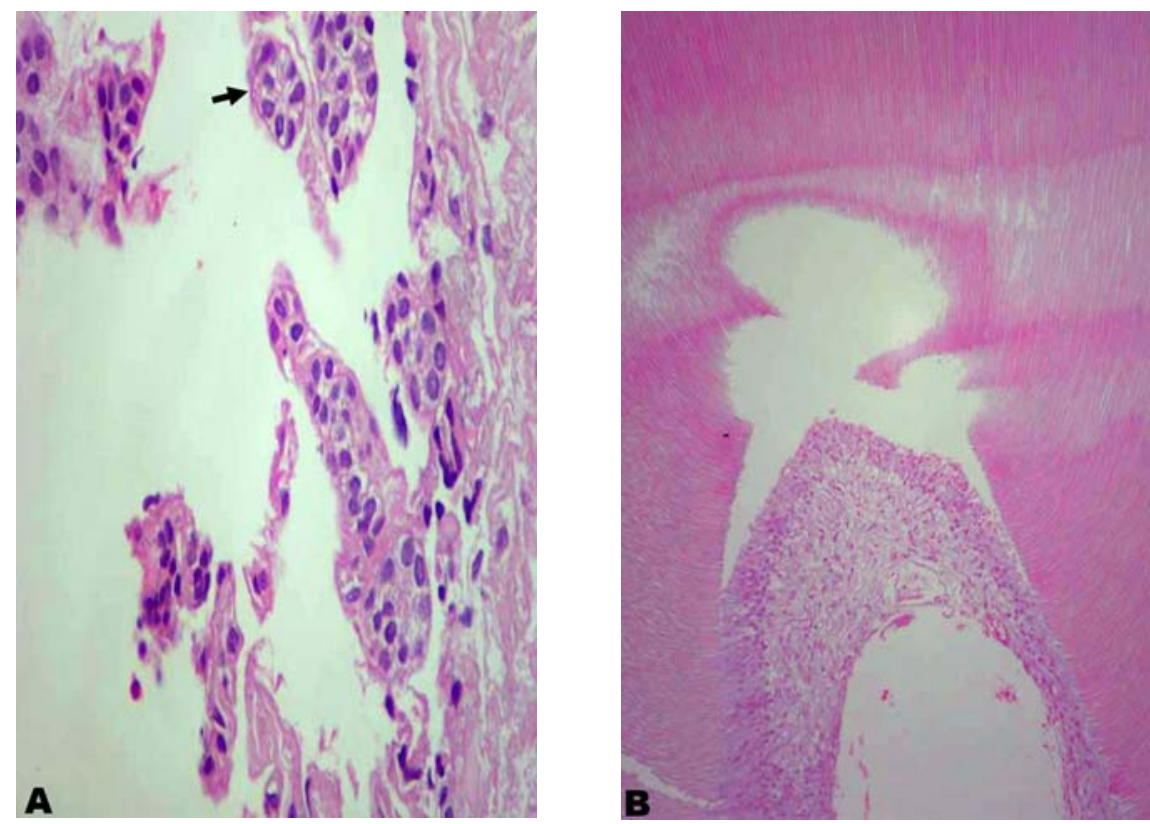

Fig. 11. Case 1: (a) Hematoxylin and Eosin (H\&E) stained showing epithelial cell proliferation with duct-like structure formations (see arrow). (b) This picture showing dentin and connective tissue in an arrangement resembling tooth structure.

In the second case, the microscopic picture of the tumor showed sheets and strands of proliferated odontogenic epithelial cells with numerous duct-like structures and globular calcific deposits (Fig. 12a). 
Sheets of hard dental structures and connective tissue, all arranged in a disorganized manner were also seen (Fig. 12b). The diagnosis was AOT associated with complex odontoma.

The microscopic picture of the biopsy from the third case revealed a cystic space lined by ameloblast and stellate reticulum-like cells with a number of ghost cells characteristic for CEOC (Fig. 13a). Surgical removal of the area of the mandible involved by the lesion was done and the whole lesion was sent again for histopathological examination. The microscopic picture at that time showed epithelial proliferation mainly in the form of anastomozing strands lined peripherally by ameloblast-like cells and contained stellate reticulum-like cells in their centers (Fig. 13b). The final diagnosis of this lesion was a CEOC associated with ameloblastoma or ameloblastoma ex CEOC.
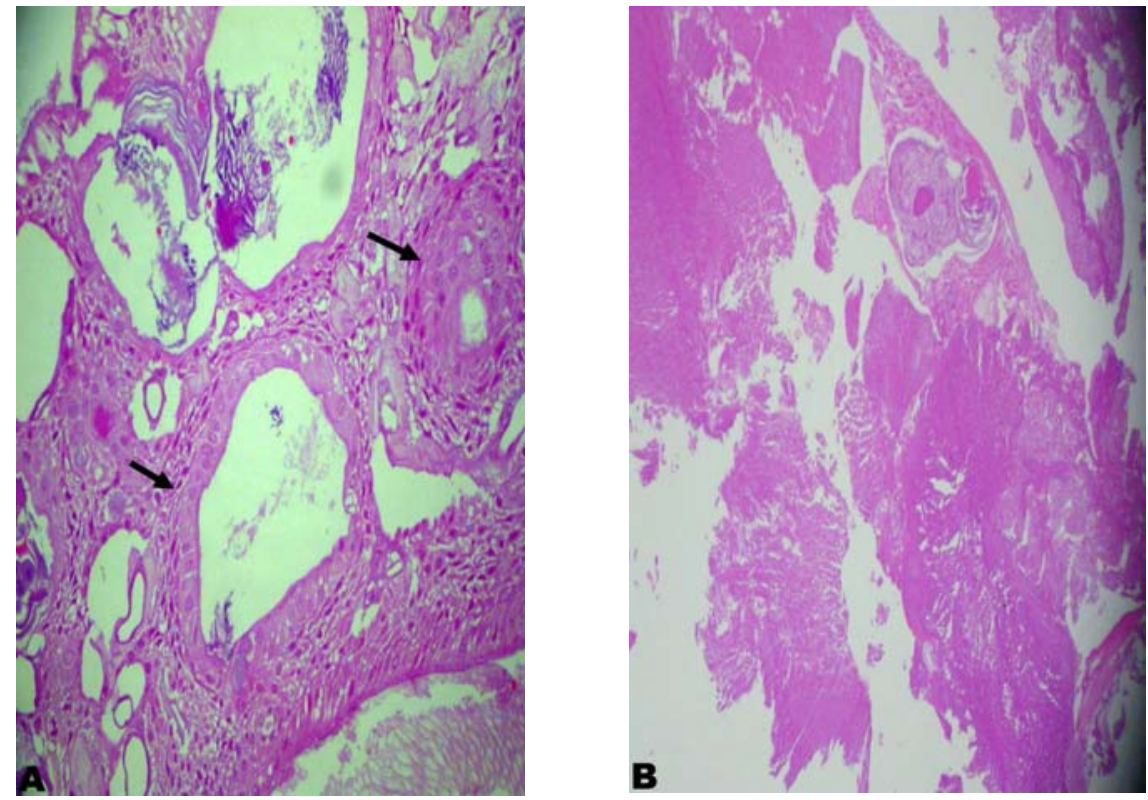

Fig. 12. Case 2: (a) Hematoxylin and Eosin (H\&E) stained section showing duct-like structures within the proliferated epithelial cells (see arrows). (b) Another area in the section of Fig. 12 showing dentin and connective tissue arranged in a disorganized manner. 

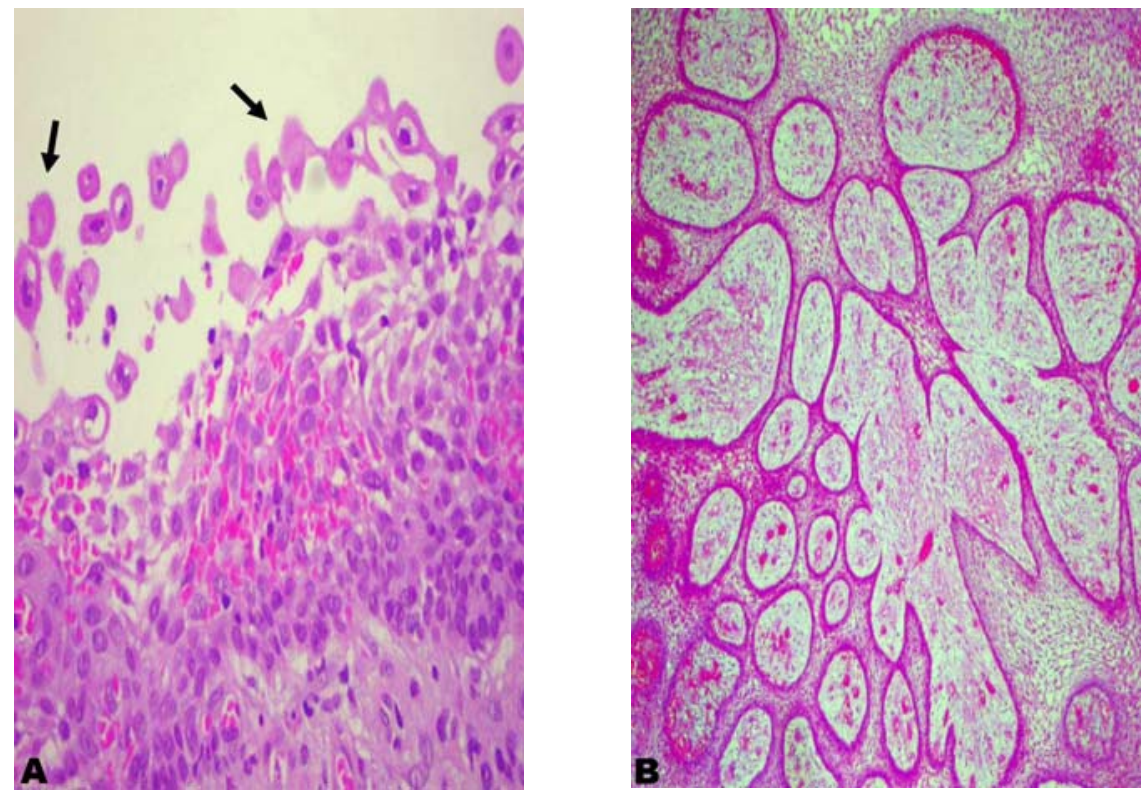

Fig. 13. Case 3: (a) Hematoxylin and Eosin (H\&E) stained showing a cyst lining consisting of ameloblast - and stellate reticulum-like cells and ghost cells (see arrows). (b) Another area in the section of Fig 13 showing proliferation of ameloblast - and stellate reticulum-like cells in a plexiform ambeloblastoma.

\section{Discussion}

AOT was first identified as a histological distinct lesion by Stafne $(1948)^{[17]}$. This tumor has been reported under various other terms, each suggesting another theory of histogenesis e.g., adenoameloblastoma ${ }^{[18,19]}$, ameloblastic adenomatoid tumor ${ }^{[20,21]}$, adenomatoid ameloblastoma ${ }^{[22]}$, odontogenic adenomatoid tumor ${ }^{[23]}$ and the most recent used name $\mathrm{AOT}^{[24]}$.

AOT accounts for about $1 \%$ to $9 \%$ of all odontogenic tumors. It is predominantly found in young and female patients, located more often in the maxilla and in most cases, it is associated with an unerupted tooth ${ }^{[25]}$.

Histologically, the tumor shows an epithelial proliferation, which is composed of polyhedral to spindle cells. Duct-like structures of columnar epithelial cells give the lesion its characteristic microscopic feature. Foci of calcific material are scattered throughout the lesion. The number, size, and degree of calcification of these foci determine how the lesion presents radiographically ${ }^{[1]}$. 
Odontomas are known as mixed odontogenic tumors because they are composed of tissue that is both epithelial and mesen'chymal in origin ${ }^{[26,27]}$. These tumors are characterized by formation of mature dental tissues in the form resembling malformed tooth (compound odontoma) or in a disorganized manner (complex odontoma $)^{[1]}$.

In the present study, we reported 2 cases of combined AOT and odontoma. To our knowledge no such combination has previously been reported in the literature. However, more than 10 cases of combined AOT and CEOT (Pindborg tumor) have been reported since 1983. This rare AOT- odontoma combination reported in the present study was found on 11- and 16-year-old patients. This was in accordance with Regezi et al., (2003) $)^{[1]}$ and Neville et al., (2002) $)^{[28]}$ who stated that the most common age of occurrence of AOT or odontoma is the second decade of life. Although the same authors reported that AOT and odontoma are found mostly in the anterior part, especially of maxilla, the present study cases are nearly found in the premolar - molar areas of the mandible. The second interesting point is that the combination between AOT and odontoma in this work occurred between 2 benign capsulated tumors nearly with the same behavior. This is important because the 2 lesions, even if they are separate, are treated the same way - simple excision without expecting risk of recurrence.

The third interesting finding about the combination is that it occurred between 2 tumors belonging to 2 different groups of origin, as the AOT belongs to the epithelial group and the odontoma belongs to the mixed group (Table 1). In this respect, it is suggested that the combined presence of AOT and odontoma may be related to the ability of AOT to induce formation of mature dental tissues in the form of compound or complex odontoma. Another suggestion is the ability of the epithelial component of odontoma to proliferate into an AOT. A similar explanation was suggested by Martin-Duverneuil et al. (2001) ${ }^{[11]}$ regarding their reported case of combined CEOT and odontoma.

The third combined odontogenic tumor reported in the present study was CEOC (Gorlin cyst) associated with ameloblastoma. CEOC was first described by Gorlin et al. (1962) ${ }^{[29]}$. In 1992, WHO classified CEOC within the odontogenic tumors ${ }^{[3]}$. According to Shear (1994) ${ }^{[30]}$, Gorlin cyst accounts for $1 \%$ of jaw cysts. 
Most cases of CEOC have features of a cyst, but in about $15 \%$ of the cases they are solid lesions ${ }^{[31]}$. The lesion appears as a painless slow-growing tumor in the maxilla or mandible, especially in the anterior part ${ }^{[28,32]}$. It usually affects the patients in the third and fourth decades ${ }^{[33]}$. Differently, the study's case was 17-year-old and the lesion occurred in the posterior part of the mandible. This may be because this case was associated with ameloblastoma.

Radiographically, CEOC shows a radiolucent area that contains different amounts of radiopacque material ${ }^{[34,35]}$. Our case being associated with ameloblastoma, it did not contain any calcific material and it appeared radiolucent in the X-ray.

Histologically, CEOC is known to show a cystic space lined by an odontogenic epithelium with the presence of variable amounts of ghost cells. Areas of calcific material may also be found ${ }^{[36]}$. The histological findings in our case were in agreement with the later features in addition to the presence of ameloblastoma tissue arising from the cyst lining. For this reason our case was diagnosed as CEOC associated with ameloblastoma or ameloblastoma ex $\mathrm{CEOC}^{[37]}$. Until 2003, the review of literature revealed only 3 cases of this combined tumor ${ }^{[37,38]}$. However, CEOC may occur in association with other odontogenic tumors, the most common is the odontomas ${ }^{[15,39-41]}$. Ameloblastoma ex CEOC is also known to occur intraosseously, appearing as cyst-like radiolucent lesions ${ }^{[42]}$. These features are similar to those of our case. Whether ameloblastoma ex CEOC should be classified as a subtype of ameloblastoma or as a subtype of CEOC may be open to discussion ${ }^{[42]}$. Buchner (1991) ${ }^{[32]}$ suggested that if the CEOC was associated with an ameloblastoma, its behavior and prognosis would be that of an ameloblastoma, not that of CEOC. Thorough study of future reported cases may provide the answers for the previous questions.

\section{Conclusions}

From the present study we can conclude the following:

1) The 2 cases of AOT associated with odontomas reported in the present work seem to be the first 2 cases reported in literature. 
2) The case of ameloblastoma ex CEOC studied here also seems to be an addition to the previously 3 cases reported in the literature.

3) The combination of the AOT and odontoma in the first two cases represent a combination of two tumors of two different origins, as AOT is derived from epithelium and odontoma is derived from both epithelium and connective tissues.

\section{Recommendations}

1) It is suggested that an item including combined odontogenic tumors should be added to the classification of odontogenic tumors.

2) Any future found association between odontogenic tumors should be studied and added to the previous reported cases to allow knowing their pathology, behavior, and the best way to treat these lesions.

\section{References}

[1] Regezi JA, Sciubba JJ, Jordan RCK. Odontogenic tumors. In Oral Pathology, St. Louis, MS: Saunders, 2003. 267.

[2] Kramer RH, Pindborg JJ, Shear M. International histological classification of tumors: Histological Typing of Ondotogenic Tumors. $2^{\text {nd }}$ ed. Berlin: Springer, 1992a. 79: 20-21, $66-68$.

[3] Kramer IR, Pindborg JJ, Shear M. The WHO Histological Typing of Odontogenic Tumors. A commentary on the Second Edition. Cancer 1992; 70(12): 2988-2994.

[4] Reichart PA, Philipsen HP. Odontogenic tumors and allied conditions. London: Quintessence, 2004. 21-23.

[5] Montes LC, Mosqueda TA, de Romero E, et al. Adenomatoid odontogenic tumor with features of calcifying odontogenic tumor (the so called combined epithelial odontogenic tumor). Clinico-pathological report of 12 cases. Euro J Cancer B Oral Oncol 1993; 29B: 221-224.

[6] Junquera Gutierrez LM, Albertos Castro JM, Floriano Alvarez P, Lopez Arranz JS. [Combined epithelial odontogenic tumor]. Rev Stomatol Chir Maxillofac 1994; 95(1): 27-29.

[7] Damm DD, White DK, Drummond JF, Poindexter JB, Henry BB. Combined epithelial odontogenic tumor: adenomatoid odontogenic tumor and calcifying epithelial odontogenic tumor. Oral Surg Oral Med Oral Pathol 1983; 55(5): 487-496.

[8] Bingham RA, Adrian JC. Combined epithelial odontogenic tumor, adenomatoid odontogenic tumor and calcifying epithelial odontogenic tumor: report of a case. J Oral Maxillofac Surg 1986; 44(7): 574-577.

[9] Chong Huat Siar, Kok Han N. Combined calcifying epithelial odontogenic tumor and adenomatoid odontogenic tumor. Int J Oral Maxillofac Surg 1987; 16(2): 214-216.

[10] Siar CH, Ng KH. The combined epithelial odontogenic tumor in Malaysians. Br J Oral Maxillofac Surg 1991; 29(2): 106-109.

[11] Miyake M, Nagahata S, Nishihara J, Ohbayashi Y. Combined adenomatoid odontogenic tumor and calcifying epithelial odontogenic tumor: report of case and ultrastructural study. $J$ Oral Maxillofac Surg 1996; 54(6): 788-793. 
[12] Mosqueda-Taylor A, Carlos-Bregni R, Ledesma-Montes C, Fillipi RZ, de Almeida OP, Vargas PA. Calcifying epithelial odontogenic tumor-like areas are common findings in adenomatoid odontogenic tumors and not a specific entity. Oral Oncol 2005; 41(2): 214215.

[13] Chen SH, Katayanagi T, Osada K, Hamano H, Inoue T, Shimono M, Takano N, Shigematsu T. Ameloblastoma and its relationship to ameloblastic fibroma: their histogenesis based on an unusual case and review of the literature. Bull Tokyo Dent Coll 1991; 32(2): 51-66.

[14] Martin-Duverneuil N, Roisin-Chausson MH, Behin A, Favre-Dauvergne E, Chiras J. Combined benign odontogenic tumors: $\mathrm{CT}$ and MR findings and histomorphologic evaluation. AJNR Am J Neuroradiol 2001; 22(5): 867-872.

[15] Pistoia GD, Gerlach RF, dos Santos JC, Montebelo Filho A. Odontoma-producing intraosseous calcifying odontogenic cyst: case report. Braz Dent $J$ 2001; 12(1): 67-70.

[16] Lin CC, Chen CH, Lin LM, Chen YK, Wright JM, Kessler HP, Cheng YS, Ellis E $3^{\text {rd }}$. Calcifying odontogenic cyst with ameloblastic fibroma: report of three cases. Oral Surg Oral Med Oral Pathol Oral Radiol Endod 2004; 98(4): 451-460.

[17] Stafne AC. Epithelial tumor associated with developmental cysts of maxilla. Report of three cases. Oral Surgery 1948; 1: 887.

[18] Bernier JL, Tiecke RW. Adenoameloblastoma. J Oral Surg Anesth Hosp Dent Serv 1950; 8(3): 259-261.

[19] Thoma KH. Adenoameloblastoma. Oral Surg Oral Med Oral Pathol 1955; 8(4): 441444.

[20] Gorlin RJ, Chaudhry AP, Pindborg JJ. Odontogenic tumors. Classification, histopathology, and clinical behavior in man and domesticated animals. Cancer 1961; 14: 73-101.

[21] Gorlin RJ, Meskin LH. Odontogenic tumors in man and animals: pathologic classification and clinical behavior. A review. Ann N Y Acad Sci 1963; 108: 722-771.

[22] Ishikawa G, Mori K. A histopathological study on the adenomatoid ameloblastoma. Report of four cases. Acta Odontol Scand 1962; 20: 419-432.

[23] Abrams AM, Melrose RJ, Howell FV. Adenoameloblastoma. A clinical pathologic study of ten new cases. Cancer 1968; 22(1): 175-185.

[24] Philipsen HP, Birn H. The adenomatoid odontogenic tumour. Ameloblastic adenomatoid tumour or adeno-ameloblastoma. Acta Pathol Microbiol Scand 1969; 75(3): 375-398.

[25] Handschel JG, Depprich RA, Zimmermann AC, Braunstein S, Kübler NR. Adenomatoid odontogenic tumor of the mandible: review of the literature and report of a rare case. Head Face Med 2005; 1: 3.

[26] Melrose RJ. Benign epithelial odontogenic tumors. Semin Diagn Pathol 1999; 16(4): 271-287.

[27] Tomich CE. Benign mixed odontogenic tumors. Semin Diagn Pathol 1999; 16(4): 308316.

[28] Neville BW, Damm DD, Allen CM, Bourqout JE. Odontogenic cysts and tumors. In Oral and Maxillofacial Pathology. Philadelphia: Saunders, 2002. 589.

[29] Gorlin RJ, Pindborg JJ. Odontogenic tumors in man and animals: pathologic classification and clinical behavior. A review. Ann N Y Acad Sci 1963; 108: 722-771.

[30] Shear M. Developmental odontogenic cysts: An update. J Oral Pathol Med 1994 23(1): $1-11$.

[31] McGowan RH, Browne RM. The calcifying odontogenic cyst: a problem of preoperative diagnosis. Br J Oral Surg 1982; 20(3): 203-212. 
[32] Buchner A. The central (intraosseous) calcifying odontogenic cyst: an analysis of 215 cases. J Oral Maxillofac Surg 1991; 49(4): 330-339.

[33] Yoshida M, Kumamoto H, Ooya K, Mayanagi H. Histopathological and immunohistochemical analysis of calcifying odontogenic cysts. J Oral Pathol Med 2001; 30(10): 582-588.

[34] Freedman PD, Lumerman H, Gee JK. Calcifying odontogenic cyst. A review and analysis of seventy cases. Oral Surg Oral Med Oral Pathol 1975; 40(1): 93-106.

[35] Farman AG, Smith SN, Nortje CJ, Grotepass FW. Calcifying odontogenic cyst with ameloblastic fibro-odontome: one lesion or two? J Oral Pathol 1978; 7(1): 19-27.

[36] Arthur J, Mark F, Lionel G. Calcifying odontogenic cyst: a clinicopathologic study of 57 cases with immunohistochemical evaluation of cytokeratin. J Oral Surg 1997 55: 108-111.

[37] Hong SP, Ellis GL, Hartman KS. Calcifying odontogenic cyst. A review of ninety-two cases with reevaluation of their nature as cysts or neoplasms, the nature of ghost cells, and subclassification. Oral Surg Oral Med Oral Pathol 1991; 72(1): 56-64.

[38] Tajima Y, Yokose S, Sakamoto E, Yamamoto Y, Utsumi N. Ameloblastoma arising in calcifying odontogenic cyst. Report of a case. Oral Surg Oral Med Oral Pathol 1992; 74(6): 776-779.

[39] Gallana-Alvarez S, Mayorga-Jimenez F, Torres-Gomez FJ, Avella-Vecino FJ, SalazarFernandez C. Calcifying odontogenic cyst associated with complex odontoma: case report and review of the literature. Med Oral Patol Oral Cir Bucal 2005; 10(3): 243-247.

[40] Hirshberg A, Kaplan I, Buchner A. Calcifying odontogenic cyst associated with odontoma: a possible separate entity (odontocalcifying odontogenic cyst). J Oral Maxillofac Surg 1994; 52(6): 555-558.

[41] Toida M, Ishimaru J, Tatematsu N. Calcifying odontogenic cyst associated with compound odontoma: report of a case. J Oral Maxillofac Surg 1990; 48(1): 77-81.

[42] Aithal D, Reddy BS, Mahajan S, Boaz K, Kamboj M. Ameloblastomatous calcifying odontogenic cyst: a rare histologic variant. J Oral Pathol Med 2003; 32(6): 376-378. 


\section{تقييم الأور ام السنية المركبة من النو احي الإكلينيكية و التصوير بالأشعة و التشخيص الميكروسكوبي}

\section{عبد الله سعيد آل مشيطو أحمد عمر اليماني}

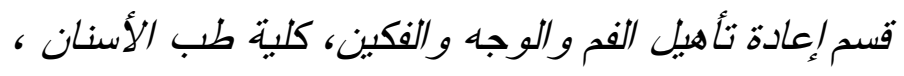
جامعة الملك عبدالعزيز، جدة ، المملكة العربية السعودية

المستخلص. عرفت الأورام السنية المركبة بتميزها باندماج الصورة

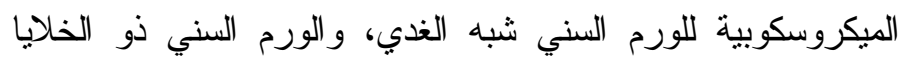

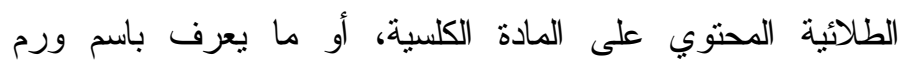

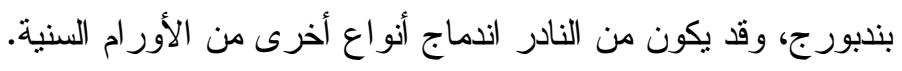

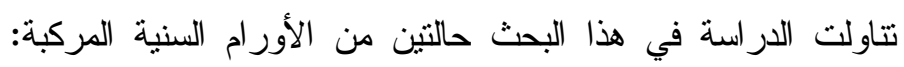

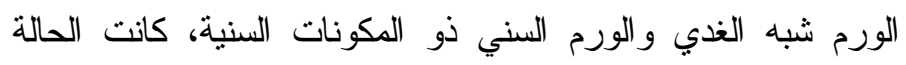

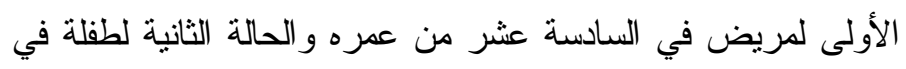

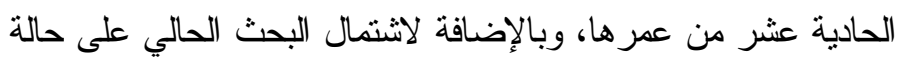

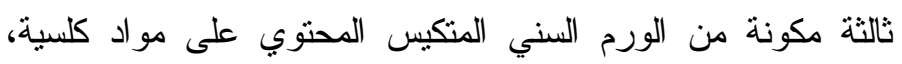

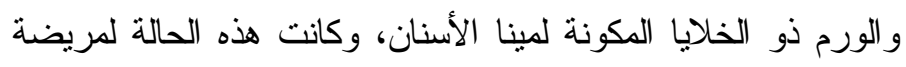

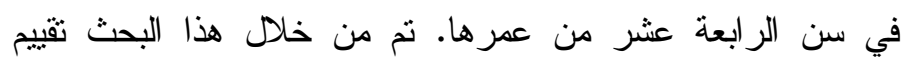

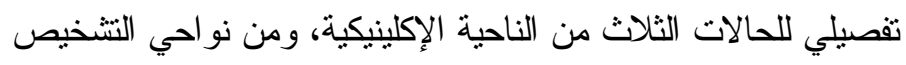

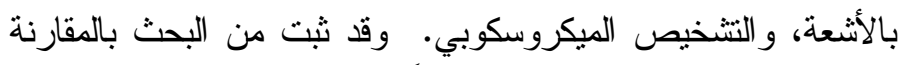

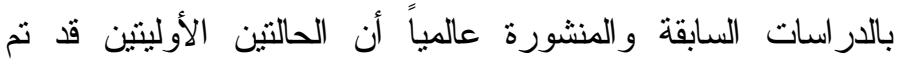

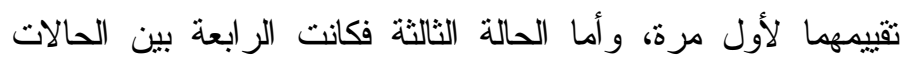
المماتلة المكتشفة سابقاً. 